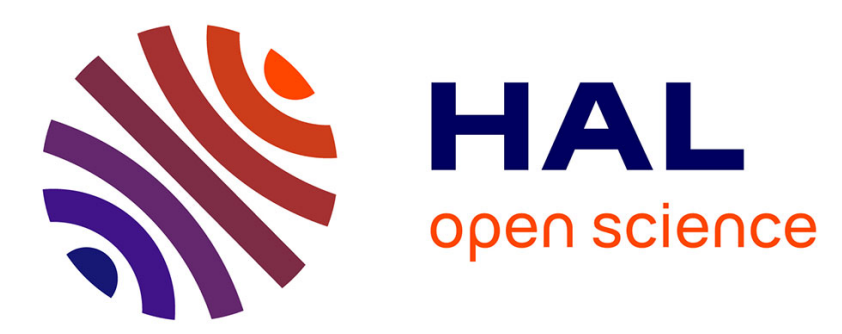

\title{
Report of Collaborative Modeling and Simulation (CoMetS) Track of WETICE 2019
}

\author{
Andrea d'Ambrogio, Grégory Zacharewicz
}

\section{To cite this version:}

Andrea d'Ambrogio, Grégory Zacharewicz. Report of Collaborative Modeling and Simulation (CoMetS) Track of WETICE 2019. WETICE 2019 - IEEE 28th International Conference on Enabling Technologies: Infrastructure for Collaborative Enterprises, Jun 2019, Napoli, Italy. pp.104-105, 10.1109/WETICE.2019.00030 . hal-02301949

\section{HAL Id: hal-02301949 \\ https://hal.science/hal-02301949}

Submitted on 25 May 2021

HAL is a multi-disciplinary open access archive for the deposit and dissemination of scientific research documents, whether they are published or not. The documents may come from teaching and research institutions in France or abroad, or from public or private research centers.
L'archive ouverte pluridisciplinaire HAL, est destinée au dépôt et à la diffusion de documents scientifiques de niveau recherche, publiés ou non, émanant des établissements d'enseignement et de recherche français ou étrangers, des laboratoires publics ou privés. 


\section{Report of \\ Collaborative Modeling and Simulation (CoMetS) track of WETICE 2019}

\author{
Andrea D'Ambrogio \\ University of Rome Tor Vergata \\ Rome, Italy \\ dambro@uniroma2.it
}

\author{
Gregory Zacharewicz \\ IMT - Mines Ales \\ Alès, France \\ gregory.zacharewicz@mines-ales.fr
}

\begin{abstract}
The 7th edition of the CoMetS track aims to bring together leading researchers and practitioners from both the modeling and simulation $(M \& S)$ community and the collaborative environments community, in order to focus on innovative research contributions that address both the use of collaborative technologies in the field of $M \& S$ and the use of $M \& S$ methodologies and tools to address the design of collaborative systems. This paper reports on the motivations of the track and the organization of its seventh edition.
\end{abstract}

\section{Motivation AND SCOPE}

Modeling and Simulation (M\&S) is increasingly becoming a central activity in the design of new systems and in the analysis of existing systems because it enables designers and researchers to investigate systems behavior through virtual representations. For this reason, $M \& S$ is gaining a primary role in many industrial and research fields, such as space, critical infrastructures, manufacturing, emergency management, biomedical systems and sustainable future. However, as the complexity of the investigated systems increases and the types of investigations widens, the cost of M\&S activities increases due to both the more complex models and the communications among a wider number and variety of $M \& S$ stakeholders (e.g., sub-domain experts, simulator users, simulator engineers, and final system users). To address the increasing costs of M\&S activities, collaborative technologies can effectively support these activities by fostering the sharing and reuse of models, by facilitating the communications among M\&S stakeholders, and more generally by integrating processes, tools and platforms.

The seventh edition track on Collaborative Modeling and Simulation (CoMetS) intends to bring together leading researchers and practitioners from both the M\&S community and the collaborative systems community, in order to focus on the different perspectives that combine collaboration and $\mathrm{M} \& \mathrm{~S}$.

From the collaboration point of view, the use of collaborative technologies is an effective tool to support the network of spatially dispersed actors typically involved in a M\&S effort. Collaboration can be applied to support $M \& S$ activities at different levels. As an example, collaboration could involve the use of distributed simulation standards (e.g., the HLA standard) or it could involve the use of co-location tools to boost interaction and cooperation between geographically dispersed $M \& S$ teams. The expected result is improved M\&S capabilities in terms of model building and evaluation activities.

On the other hand, from the modeling and simulation point of view, simulation tools can be significantly used to analyze and increase the quality offered by collaborative environments. The ability to model and simulate the multi-dimensional aspects of collaboration is itself a significant challenge that contributes to the achievement of increased levels of quality and productivity.

The CoMetS track is now at its seventh edition [1], [2], [3], [4], [5] and [6]. It still focuses on innovative research contributions that address collaboration issues in the field of $M \& S$ and vice versa, i.e., contributions that use $M \& S$ methodologies and tools to address the design of collaborative environments. A combination of both issues in the same venue further contributes to the understanding of the underlying mechanisms that can affect the quality of service delivered by collaborative environments for M\&S.

\section{ACCEPTED PAPERS}

The papers submitted to the track have undergone a thorough review process. Each paper has been reviewed by at least two members of the program committee. At the end of the review process, the following 3 full papers have been accepted for publication and presentation at the conference:

- Using Patterns to parameterize the execution of Collaborative Tasks (full paper): during the execution of a process, managing the collaboration inside a task performed by various actors is not straightforward due to possible changes of the processs context and the collaboration strategy. Process management solutions which describe the collaboration at modeling time offer a rigid control for conducting such collaborative tasks and thus cannot adapt to changes. To enable a flexible execution of collaborative tasks, the authors propose using a latebinding mechanism to allow process actors, at execution time, choosing or adapting strategies to perform their 
collaboration. To do so, first they model collaboration strategies as process patterns providing different ways to implement a collaborative tasks at execution time. These collaboration patterns describe how to establish necessary relations for coordinating different instances of the task, for sharing and exchanging working artifacts among actors performing those instances. Then they define actions to execute collaborative tasks. These actions take collaboration patterns as parameters. Thus, by letting process actor selecting a suitable collaboration pattern, they allow binding dynamically a collaborative task to its implementation flexibly.

- A collaborative decision approach for alignment of heterogeneous models (full paper): the paper describes the design of complex systems that goes through a multiview paradigm in which separate teams, from different business viewpoints, build partial models describing the system. As they are expressed in different languages, these partial models are called heterogeneous models. To maintain the global systems consistency, the authors propose a collaborative approach that combines Group Decision Making (GDM) and Model-Driven Engineering. This paper presents a metamodel for collaborative decision elaboration via a set of decision policies which are instances of GDM patterns. The proposed approach is illustrated by use of a hospital Emergency Department case study and is supported by a tool allowing models alignment through GDM based processes.

- A BPMN/HLA-Based Methodology for Collaborative Distributed DES (full paper): in many domains, DiscreteEvent Simulations (DES) are typically used to reproduce the behavior of a certain system or process, where events are processed one after another in chronological and sequential order. Classical DES will no longer be a possible solution for Complex and Large-scale systems, System of Systems (SoS), and Performance Evaluation Systems that compare multiple different simulations running simultaneously in parallel. Advances in network and communications made the Distributed Simulation (DS) approach one of the best solutions for the simulation of complex systems. One of the challenges faced when developing a DS from DES components is the federation behavior including time management and synchronization between these components. In most of the traditional DES platforms, simulations cannot exchange messages, nor change the configuration at run time. This makes the DES connection and integration very hard and, in some cases, impossible to implement. The paper presents the method used to integrate different DES components, using HighLevel Architecture (HLA) Evolved Standard, Business Process Model and Notation (BPMN), and Jaamsim, a Java open source DES.

\section{ACKNOWLEDGMENT}

The track organizers sincerely express their gratitude to the program committee members for their thorough effort on setting up the track and reviewing submitted papers.

\section{REFERENCES}

[1] A. D'Ambrogio, D. Gianni, J. Fuchs, and G. Iazeolla, "Ieee first workshop on collaborative modeling and simulation (comets 2010)," in 2010 19th IEEE International Workshops on Enabling Technologies: Infrastructures for Collaborative Enterprises, June 2010, pp. 122-123.

[2] D. Gianni, A. D'Ambrogio, J. Fuchs, and G. Iazeolla, "Collaborative modeling and simulation track report - comets 2011," in 2011 IEEE 20th International Workshops on Enabling Technologies: Infrastructure for Collaborative Enterprises, June 2011, pp. 162-163.

[3] D. Gianni, A. DAmbrogio, J. Fuchs, and G. Iazeolla, "Comets track report: 3rd track on collaborative modeling and simulation," in 2012 IEEE 21 st International Workshop on Enabling Technologies: Infrastructure for Collaborative Enterprises, June 2012, pp. 211-213.

[4] A. D'Ambrogio, D. Gianni, J. Fuchs, and G. Iazeolla, "Track report of collaborative modeling and simulation (comets 2014)," in 2014 IEEE 23rd International WETICE Conference, June 2014, pp. 197-198.

[5] A. D'Ambrogio, G. Zacharewicz, and D. Gianni, "Report of collaborative modeling and simulation (comets) track of wetice 2016," in 2016 IEEE 25th International Conference on Enabling Technologies: Infrastructure for Collaborative Enterprises (WETICE), June 2016, pp. 116-117.

[6] A. D'Ambrogio and G. Zacharewicz, "Report of collaborative modeling and simulation (comets) track of wetice 2018," in 2018 IEEE 27th International Conference on Enabling Technologies: Infrastructure for Collaborative Enterprises (WETICE), June 2018, pp. 119-120. 